\title{
A judicialização de demandas odontológicas e o direito à saúde
}

\author{
Judicialization of dental demands and the right to health
}

Beatriz Cristina de Freitas', Dagmar de Paula Queluz'

DOI: $10.1590 / 0103-1104202012611$

RESUMO O arcabouço jurídico-legal que estruturou o Sistema Único de Saúde influenciou significativamente a evolução da saúde bucal coletiva, no entanto, seu acesso ainda constitui um dos principais desafios da gestão dos sistemas de saúde. À luz dos direitos humanos, o direito à saúde bucal é um direito indissociável da saúde geral. Objetivou-se analisar a judicialização de demandas odontológicas fundamentadas no direito à saúde previsto na Constituição Federal de 1988. Trata-se de um estudo exploratório, descritivo, realizado em base de dados secundários, obtidos nos acórdãos de segunda instância do Tribunal de Justiça de São Paulo, de janeiro de 2016 a abril de 2019. Os resultados foram categorizados e analisados por estatística descritiva. As ações judiciais relativas à odontologia buscam, principalmente: indenizações por danos morais e materiais - 336 acórdãos (65\%); indenização pela má qualidade da prestação de serviços odontológicos - 114 acórdãos (22\%); e negativa de cobertura de procedimento e/ou materiais, por planos de saúde - 63 acórdãos (13\%). As ações por erro odontológico aumentaram 305\%, passando de 22 acórdãos, em 2016, para 99, em 2018. Conclui-se que as demandas judiciais referentes à odontologia estão mais voltadas às indenizações materiais e morais da prestação de serviços do que ao acesso e à efetivação de direitos constitucionais à saúde bucal.

PALAVRAS-CHAVE Judicialização da saúde. Odontologia. Assistência odontológica.

\begin{abstract}
The legal-regulatory framework that structured the Unified Health System significantly influenced the evolution of collective oral health, however, access is still one of the main challenges of health systems management. In the light of human rights, the right to oral health is an inseparable right of general health. The objective of this research was to analyze the judicialization of dental demands based on the right to health provided for in the 1988 Federal Constitution. This is an exploratory, descriptive study, carried out in secondary database, obtained in the court decision of the second instance of the Court of Justice of São Paulo, from January 2016 to April 2019. The results were categorized and analyzed by descriptive statistics. The lawsuits related to Dentistry seek, mainly: indemnity for moral and material damages - 336 court decision (65\%), indemnity for poor quality of dental services - 114 court decisions (22\%), and negative procedural and/ or material coverage. by health insurance - 63 court decisions (13\%). Lawsuits for dental error increased by $305 \%$ from 22 court decision, in 2016, to 99 court decision, in 2018. It is concluded that the judicial demands in the dental area are more focused on the material and moral indemnities of the provision of dental services than for access and enforcement of constitutional rights to oral health.
\end{abstract}

KEYWORDS Health's judicialization. Dentistry. Dental care.

1 Universidade Estadual de Campinas (Unicamp) -

Campinas (SP), Brasil. beatrizcristina.freitas@ gmail.com 


\section{Introdução}

A reestruturação do sistema de saúde brasileiro, sob a ótica do direito e não mais como um benefício, é fruto de uma grande mobilização - não somente de profissionais da saúde e técnicos, mas também da sociedade - em busca de um sistema de saúde menos excludente. A reforma sanitária trouxe à tona os problemas sanitários da época e abordou os princípios norteadores que embasaram a criação do Sistema Único de Saúde (SUS), moldando substancialmente o que viria a ser o texto constitucional promulgado em $1988^{1}$.

Dessa forma, a Constituição Federal de 1988 definiu a saúde como direito do cidadão e dever do Estado. Em seguida, a Lei Orgânica da Saúde, editada em 1990, estruturou as condições para a promoção, a proteção e a recuperação da saúde, além do funcionamento dos serviços relacionados à área, estruturando o SUS².

Observa-se que o arcabouço jurídico-legal que estruturou o SUS reafirmou os propósitos da reforma sanitária, trazendo a noção de direito à saúde e de integralidade para o sistema de saúde brasileiro, também influenciando, significativamente, a evolução da saúde bucal coletiva ${ }^{1}$.

A II Conferência Nacional de Saúde Bucal (CNSB), realizada em 199333, trouxe no seu escopo algumas considerações sobre a inserção da saúde bucal no SUS, e o modelo proposto refletiu os conceitos básicos da reforma sanitária'.

A inclusão da saúde bucal na Estratégia Saúde da Família (ESF) se deu no ano 2000, na tentativa de romper com modelos antigos de assistência à saúde bucal, reorientando o processo de trabalho e a atuação da equipe no âmbito dos serviços públicos, centrando-se no tripé território-família-comunidade e na humanização da atenção 4 .

Em 2004, com o lançamento do Programa Brasil Sorridente ${ }^{5}$, a saúde bucal passou a ter uma política pública consonante com os princípios do SUS' ${ }^{1}$, de forma a cumprir com os objetivos de uma proposição para reorientar o modelo de atenção em saúde bucal ${ }^{6}$, ampliando e qualificando a atenção primária e especializada ${ }^{7}$.

A inserção da saúde bucal e das práticas odontológicas no SUS aconteceu de forma paralela e distanciada do processo de organização dos demais serviços de saúde ${ }^{8}$, e organizou-se dentro de um contexto privatista. Seu avanço científico e tecnológico transformou esse benefício em estratégias de mercado, tornando a odontologia excludente e deixando-a na contramão dos princípios constitucionais $\mathbf{1}$.

Sob o ponto de vista da saúde integral, o direito à saúde, previsto pela Constituição Federal de $1988^{\circ}$, é definido como o direito a bens, serviços e produtos, assim como às condições necessárias para atingir o mais alto padrão de saúde física e mental, não se restringindo aos cuidados em saúde, mas englobando o direito aos determinantes sociais que afetam diretamente o processo saúde-doença.

Assim, entende-se que o direito à saúde é um direito inclusivo, que incorpora outros direitos sociais, que interagem entre si, como nutrição, moradia, acesso a água potável e segurança, condições sanitárias adequadas e de trabalho, bem como a ambiente saudáveis $^{10}$, ou seja, está intimamente relacionado a determinantes políticos, econômicos, sociais, culturais e ambientais, que afetam a saúde como um todo"11.

A II CNSB trouxe a saúde bucal como um direito humano fundamental para todos ${ }^{3}$. Do mesmo modo, para assegurar o direito à saúde bucal como indissociável da saúde geral, a Declaração de Liverpool, elaborada pela Organização Mundial da Saúde (OMS) em parceria com a Associação Internacional para a Investigação Dental (IADR), a Associação Europeia para a Saúde Pública Dental (EADPH) e a Associação Britânica para o Estudo da Odontologia Comunitária (BASCD) 11, apoia, em seu preâmbulo, que a saúde bucal é direito humano básico.

Além disso, quando a Constituição Federal de 1988 trouxe os princípios da universalidade e da integralidade do direito à saúde, não colocou limitações às questões da saúde bucal ${ }^{12}$. 
Todo o arcabouço jurídico favorece a legitimação do direito à saúde bucal. Neste sentido, faz-se necessário compreender como a população se vê enquanto portadora deste direito ${ }^{13}$, e como seria possível incrementar seus poderes, tanto em termos técnicos quanto políticos (empowerment), na definição de prioridades e na tomada de decisões sobre saúde ${ }^{14}$.

A partir de 1980, surgiram as primeiras recorrências à justiça em busca da efetivação de direitos à saúde, e um dos exemplos mais notórios disso foi o tratamento para o vírus HIV ${ }^{15}$. Em função de todo o simbolismo, da vulnerabilidade dos doentes e repercussão social, medicamentos e procedimentos médicos passaram a ser requeridos através da justiça ${ }^{15}$. Esse movimento ganhou complexidade e proporções importantes, tanto para a gestão da saúde quanto para o judiciário e autoridades, e acabou moldando substancialmente a política de assistência farmacêutica do SUS, ficando conhecido ao longo do tempo como a 'judicialização da saúde'15.

A progressiva incorporação dos direitos sociais, associada aos desafios de sua implementação pelo Estado, levou esses direitos ao crivo do judiciário para sua efetivação. Dessa forma, ações e serviços de saúde, bem como a noção de direito à saúde, ganharam relevância pública ${ }^{15}$.

Esse fenômeno envolve aspectos políticos, sociais, éticos e sanitários, que vão muito além de seu componente jurídico e da gestão de serviços públicos ${ }^{16}$. Por isto, a efetivação judicial do direito à saúde tem gerado fortes debates em diversos espaços sociais ${ }^{15}$. Segundo o Relatório Justiça em Números (2017), do Conselho Nacional de Justiça (CNJ), considerando os processos ajuizados e em trâmite nos diversos níveis judiciais, até 2016, havia 1.346 .931 processos referentes à judicialização da saúde ${ }^{17}$.

Essas demandas da judicialização da saúde pública envolvem o acesso a medicamentos, tratamentos, insumos, materiais e equipamentos ${ }^{\mathbf{1 8}}$. Na saúde suplementar, as demandas espelham, principalmente, negativas de cobertura, reajustes (por sinistralidade e mudança de faixa etária) e descredenciamento de rede de prestadores de serviço ${ }^{19}$.
A judicialização da saúde é um fenômeno complexo e muito discutido, ainda não há consenso sobre quais são as suas reais consequências no Brasil. Por um lado, sugere-se a produção de efeitos negativos na governabilidade, com intervenção do judiciário na gestão das políticas públicas de saúde, e no desenvolvimento das ações de saúde locais ${ }^{20}$. Por outro lado, pondera-se que a litigação das demandas da saúde pode também apontar falhas sistêmicas na gestão e efetivação das políticas públicas de saúde ${ }^{\mathbf{1 6}, 21}$.

Basicamente, essas demandas judiciais buscam a efetivação do direito à saúde, e as mais discutidas se referem à busca de acesso à assistência à saúde, a 'bens e serviços' de saúde ${ }^{18}$. Mas, e a saúde bucal? Será que a população brasileira também busca a justiça para a efetivação do seu direito à saúde bucal?

$\mathrm{O}$ acesso à saúde bucal tem sido discutido na literatura científica, e no contexto brasileiro, mas a universalização deste acesso ainda se constitui como um dos principais desafios da gestão dos sistemas locais de saúde a serem enfrentados para a efetivação do SUS como modelo de política pública ${ }^{22}$.

É nesse contexto que se fundamenta a hipótese aqui apresentada. Será que as dificuldades de acesso à saúde bucal têm fomentado ações judiciais para acesso a tratamento odontológico como forma de legitimação e efetivação do direito à saúde bucal? Para responder a esta pergunta, a presente pesquisa teve como objetivo analisar a judicialização de demandas odontológicas levadas ao Tribunal de Justiça de São Paulo (TJSP), para a legitimação do direito à saúde bucal e $o$ acesso a tratamento odontológico.

\section{Material e métodos}

\section{Desenho do estudo}

Trata-se de um estudo exploratório, descritivo, realizado em base de dados secundários, obtidos nos acórdãos de segunda instância do 
TJSP. O acórdão se constitui da decisão judicial proferida em segundo grau de jurisdição por uma câmara/turma de um tribunal. As decisões judiciais recebem este nome por serem proferidas de forma colegiada e refletirem o acordo de mais de um julgador.

Para a análise proposta, o estado de São Paulo foi escolhido por dois motivos: 1) por ser o mais populoso do País, com o maior Produto Interno Bruto (PIB) nacional ${ }^{23}$, e possuir um dos sistemas de saúde mais bem estruturados, com uma ampla rede de serviços, e, portanto, receber grande volume de demandas por 'bens' e serviços de saúde; 2) pela disponibilidade on-line de seus dados. O estado de São Paulo, localizado na região Sudeste do Brasil, é composto por 645 municípios e apresenta, atualmente, uma população de cerca de 44.749.699 habitantes. Sua capital, São Paulo, é também o município mais populoso do País, com 12.038.175 habitantes ${ }^{23}$.

\section{Amostra e período do estudo}

Para compor a amostra, foram selecionados todos os acórdãos relacionados à judicialização de demandas odontológicas, no período de janeiro de 2016 a abril de 2019.

\section{Fonte dos dados}

Por se tratarem de decisões colegiadas, foram analisados os acórdãos de segunda instância e as decisões monocráticas, com os processos transitados em julgado, tendo em vista o encerramento da ação nessa instância, da possibilidade de produção de matéria fático-probatória, o que não acontece com as decisões de primeira instância. Foram analisados os acórdãos relativos ao SUS e à saúde suplementar. O período de análise foi escolhido de acordo com os seguintes critérios: a) possibilidade de analisar a evolução das demandas em um maior período; b) disponibilidade on-line dos dados de segunda instância.
Os dados secundários utilizados pelo presente estudo foram obtidos no site do TJSP - http://esaj.tjsp.jus.br/cjsg/consultacompleta, acesso à jurisprudência, por meio das palavras-chave e dos termos mais utilizados na plataforma: tratamento odontológico, SUS, plano de saúde e odontologia.

\section{Variáveis do estudo}

Os dados coletados foram inseridos em uma planilha do Microsoft Excel $^{\circledR}$ e as variáveis analisadas foram: 'municípios' do estado de São Paulo (645 municípios); 'ano' (janeiro de 2016 a abril de 2019); e 'tipo de demanda odontológica' judicializada, 'especialidade odontológica' envolvida.

\section{Análise dos dados}

Foi realizada uma análise por estatística descritiva (média, desvio padrão, frequência absoluta e percentual), para uma análise exploratória.

\section{Considerações éticas}

Por se tratarem de dados secundários, disponíveis na plataforma eletrônica do TJSP, e não havendo pesquisa com seres humanos, não há necessidade de avaliação pelo Comitê de Ética em Pesquisa, estando em conformidade com as normas previstas na Resolução $n^{0} 466 / 12$, do Conselho Nacional de Saúde.

\section{Resultados}

De acordo com a estratégia de busca, foram identificados 517 acórdãos (decisões judiciais) no período analisado. Entre 2016 e 2018, foi observado um aumento de $48 \%$ no número de acórdãos, passando de 130 (2016) para 192 (2018) (tabela 1). 
Tabela 1. Acórdãos identificados por ano analisado

\begin{tabular}{lrr}
\hline Ano & $\mathbf{n}$ & $\%$ \\
\hline 2016 & 130 & 25,15 \\
2017 & 151 & 29,21 \\
2018 & 192 & 37,14 \\
Até abril - 2019 & 44 & 8,5 \\
Total & 517 & 100 \\
\hline
\end{tabular}

Fonte: Elaboração própria baseada em: Tribunal de Justiça de São Paulo, 2016 - 2019.

Foi identificada uma dispersão de acórdãos compreendendo vários municípios do estado de São Paulo (tabela 2), mas houve uma concentração em outros, como: São
Paulo - 19,53\% (n=101); Ribeirão Preto $1,74 \%$ (n=9); Jundiaí - 1,54\% (n=8); Campinas - 1,16\% (n=6); e São Bernardo do Campo $-1,16 \%(n=6)$.

Tabela 2. Municípios com maior frequência de acórdãos

\begin{tabular}{lrr}
\hline Municípios & $\mathbf{n}$ & $\%$ \\
\hline São Paulo & 101 & 19,53 \\
Ribeirão Preto & 9 & 1,74 \\
Jundiaí & 8 & 1,54 \\
Campinas & 6 & 1,16 \\
São Bernardo do Campo & 6 & 1,16 \\
Santo André & 6 & 1,16 \\
Sorocaba & 6 & 1,16 \\
São José dos Campos & 5 & 0,96 \\
São José do Rio Preto & 5 & 0,96 \\
Santos & 4 & 0,77 \\
Guarulhos & 4 & 0,77 \\
Bauru & 4 & 0,77 \\
Araçatuba & 3 & 0,28 \\
Marília & 3 & 0,38 \\
Piracicaba & 2 & 0,38 \\
Total & 2 & 32,72 \\
\hline
\end{tabular}

Fonte: Elaboração própria baseada em: Tribunal de Justiça de São Paulo, 2016 - 2019.

As ações judiciais relativas à odontologia tinham como 'demandas', principalmente: indenizações por danos morais e materiais - 336 acórdãos (65\%); indenização pela má qualidade da prestação de serviços odontológicos - 114 acórdãos (22\%); e negativa de cobertura de procedimento e/ou materiais, por planos de saúde - 63 acórdãos (13\%).

Em 177 acórdãos, as ações judiciais buscavam indenização por erro odontológico (tabela 3). As ações por erro odontológico aumentaram $305 \%$ no período analisado, passando de 22 acórdãos, em 2016, para 99 acórdãos, em 2018 (tabela 3). 
Tabela 3. Número de acórdãos relacionados às ações por erro odontológico

\begin{tabular}{lrr}
\hline Ano & $\mathbf{n}$ & $\%$ \\
\hline 2016 & 22 & 12,43 \\
2017 & 39 & 22,04 \\
2018 & 90 & 50,95 \\
Até abril - 2019 & 26 & 14,58 \\
Total & 177 & 100 \\
\hline
\end{tabular}

Fonte: Elaboração própria baseada em: Tribunal de Justiça de São Paulo, 2016 - 2019.

Em 56,5\% dos acórdãos, foi possível identificar a especialidade odontológica envolvida na demanda, sendo as mais citadas: prótese (22,6\%); implante (10,05\%); ortodontia (11,85\%); negativa de cobertura, por planos de saúde (4,5\%); e endodontia (3,5\%).

Entre os principais tipos de demandas dos processos, estão envolvidas questões relacionadas a erro ou imperícia do cirurgião-dentista, ao uso de técnicas inadequadas ou materiais de baixa qualidade, a uma não concretização dos resultados esperados pelo paciente, devido à sua alta expectativa ou falta de comunicação entre o cirurgião-dentista e o paciente, e à negativa de cobertura de órteses e próteses ligadas a procedimentos cirúrgicos odontológicos, por parte de operadoras de planos de saúde.

\section{Discussão}

O presente estudo analisou a judicialização de demandas odontológicas levadas ao TJSP, para a legitimação do direito à saúde bucal e o acesso a tratamento odontológico.

A dispersão do número de processos, analisada pela variável 'municípios', aponta que as ações judiciais relativas à odontologia estão ocorrendo em vários municípios do estado, e a concentração em alguns é justificada pelo porte populacional.

Quanto à análise da variável ‘demandas odontológicas', pode-se observar que as demandas judiciais referentes à odontologia não buscam acesso a tratamento odontológico, mas estão mais relacionadas à conduta clínica do cirurgião-dentista e aos aspectos éticos da prática odontológica. Essa característica das ações judiciais de demandas odontológicas também foi observada por Cavalcanti et al. (2011) $\mathbf{2 4}$.

Diferentemente do que ocorre em outras áreas da saúde, nas quais a judicialização para o acesso a bens e serviços de saúde busca, através da justiça, a efetivação do direito previsto na Constituição Federal de 1988 e não efetivado por vias administrativas, a judicialização de demandas odontológicas busca indenizações por danos materiais ou morais.

Essa característica da judicialização das demandas odontológicas pode apresentar dois cenários para interpretação e análise: um no qual o cirurgião-dentista figura, cada vez mais, como demandado em ação de responsabilidade civil, o que não é objeto deste estudo, mas é preocupante; e outro no qual, além dos desafios para a melhoria do acesso a tratamentos odontológicos apontados por Fonseca et al. (2017) ${ }^{22}$, a população não parece ter compreensão de que o direito à saúde bucal não é indissociável do direito à saúde. $\mathrm{O}$ fato de não se ter identificado nenhum acórdão no qual a decisão judicial refletisse a concessão de um tratamento ou acesso a um tratamento com base em tal direito permite esta suposição.

A Constituição Federal de 1988 elevou o direito à saúde a direito fundamental (Art. $196 \mathrm{CF} / 88)^{9}$, ainda que, para alcançar a efetivação deste direito, outros direitos sociais sejam indispensáveis ${ }^{\mathbf{1 2}}$. A partir dela, as políticas nacionais de saúde buscaram garantir a provisão de cuidados em saúde e o acesso 
equitativo a seus determinantes, como água potável, nutrição e condições sanitárias adequadas. É notório que a saúde bucal também é um direito indissociável da saúde como um todo, nos diversos ciclos de vida. Desde os primeiros estímulos para o desenvolvimento facial adequado, propiciado pela amamentação natural dos bebês, até a interconexão entre a saúde geral e a saúde bucal da pessoa idosa, devido às características acumulativas das doenças bucais e à susceptibilidade às doenças crônicas.

A população em geral desconhece grande parte dos direitos sociais, e a compreensão do direito à saúde bucal ainda é muito incipiente ${ }^{12}$. Além disto, segundo Martinez e Albuquerque (2017), outros determinantes sociais, como a baixa renda da população, podem estar fortemente associados às doenças bucais, já que as carências econômicas influenciam negativamente a qualidade da alimentação e o acesso a bens e serviços odontológicos.

É possível supor, no contexto brasileiro, que as dificuldades econômicas, a educação deficiente e a baixa renda per capita são fatores que interferem na mobilização da população em torno de interesses e necessidades de saúde comuns, contribuindo para uma baixa capacidade organizativa e um déficit de participação cívica e política ${ }^{24}$.

Todo um contexto histórico de exclusão de acesso à atenção odontológica no passado revela uma distribuição desigual de bens e serviços de saúde, bem como um reduzido capital social e consequente baixo empoderamento na busca da legitimação de direitos em saúde bucal ${ }^{24}$.

Fernandes e Ferreira (2010), em pesquisa entre usuários de uma clínica de ensino, observaram que os usuários do SUS apresentaram baixa consciência do direito ao atendimento odontológico ${ }^{\mathbf{1 4}}$. Seus dados refletiram uma desinformação da população, e uma falta de reconhecimento da saúde bucal como direito social ${ }^{14}$.

Analisando essa questão sobre a ótica da teoria do habitus, de Pierre Bordieu, pode-se observar todo um conjunto de experiências passadas conformando percepções, apreciações e ações sociais. Para Bordieu, a maior parte das ações dos agentes sociais é produto entre um habitus e a conjuntura social em que se insere, de uma situação histórica ${ }^{25}$.

Fonseca et al. (2015) ${ }^{\mathbf{2 6}}$ apontam, na tentativa de compreender as vivências e as expectativas de mulheres, usuárias dos serviços odontológicos do SUS, em relação à sua saúde bucal, que, para a maior parte delas, os serviços de saúde bucal não fizeram parte de sua vida passada, e, portanto, seus problemas dentários sequer foram percebidos como uma necessidade, o que moldou suas expectativas futuras em relação à saúde bucal.

Conhecimentos técnicos e específicos de várias ordens permeiam as ações, opções e práticas sociais. A conduta social passa a ser baseada em conhecimentos com origem em discussões das quais os sujeitos não participam e nem teriam condições de participar. Estão em um nível de elaboração em que, como leigos, não poderiam contribuir. Apenas assumem e respeitam a legitimidade que esses sistemas adquirem na sociedade ${ }^{26}$.

Para a legitimação do direito à saúde bucal, faz-se necessário um esforço para melhorar a educação, o habitus social, o acesso e a conscientização da população para uma ampla participação da sociedade na efetivação das políticas públicas de saúde e, no caso da odontologia, na legitimação do direito à saúde bucal.

As condições dentárias são, sem dúvida, alguns dos mais significativos sinais de exclusão social27.

Segundo Abreu-de-Jesus e Assis, citados por Fonseca et al. (2017) ${ }^{22}$, a aceitabilidade de um serviço de saúde abrange o subjetivo, o social e o quão significativa é a saúde para o indivíduo.

Além disso, para se promover saúde, faz-se necessário que os indivíduos estejam em condições de exercer maior controle sobre suas vidas, aumentando, assim, as chances de serem mais saudáveis. Tais condições são essenciais para o incremento do poder técnico e político das comunidades (empowerment) na fixação de prioridades e tomada de decisões, e na 
definição e implementação de estratégias para alcançar melhores níveis de saúde ${ }^{\mathbf{1 1}}$.

Outro aspecto que chama a atenção nos resultados encontrados é que a base legal para a interposição das demandas fundamenta-se no Código de Defesa do Consumidor (CDC/90), e não no direito à saúde previsto na Constituição Federal de 1988, ou seja, a relação é tipicamente de consumo, regulado pelas relações de compra e venda do mercado. Esta característica da saúde bucal é fortemente marcada pelas estruturas de conformação social do atendimento odontológico'.

A prestação da atenção odontológica sempre esteve relacionada ao atendimento privado e financiamento direto da atenção, essa concepção ainda permeia o ideário da população. Apesar dos avanços trazidos pela Política Nacional de Saúde Bucal, e da incorporação da atenção à saúde bucal na ESF, ainda não houve uma consciência social do direito à saúde bucal.

Não se trata de afirmar que a judicialização da saúde é um instrumento necessário para a efetivação do direito à saúde, mas a busca desse poder para acesso à assistência à saúde bucal demonstraria uma maior compreensão do alcance desse direito ${ }^{15}$.

Alguns autores ressaltam que um dos grandes conflitos atuais tem, de um lado, o direito à saúde garantido por lei, e de outro, o mercado, que condiciona a saúde ao poder de compra"1.

No período analisado, foram identificados 517 acórdãos no estado de São Paulo. No entanto, houve um aumento de $48 \%$ no número de processos, de 2016 a 2018, tendência que também foi observada por outros autores ${ }^{19}$. O aumento dos processos contra os cirurgiões-dentistas apresenta uma situação que demanda mais análises e discussões.

A falta de estudos que analisem a judicialização de demandas odontológicas para a efetivação do direito à saúde dificulta melhores comparações, e é uma limitação deste estudo.

\section{Considerações finais}

A pesquisa contemplou analisar a judicialização de demandas odontológicas levadas ao TJSP, para a legitimação do direito à saúde bucal e o acesso a tratamento odontológico. Neste sentido, pode-se concluir que as demandas judiciais na área odontológica estão mais voltadas às indenizações materiais e morais da prestação de serviços odontológicos do que ao acesso, à efetivação e legitimação de direitos constitucionais à saúde bucal.

Uma das questões centrais para a legitimação dos direitos à saúde bucal está na maior compreensão social do alcance destes direitos. Desde a criação do SUS, e a inserção da saúde bucal na ESF, várias políticas, ações e medidas foram implementadas no sentido de reconhecer o direito à saúde bucal e o acesso a serviços de saúde bucal como um direito de todos, mas este processo ainda se coloca como um imenso desafio.

\section{Colaboradores}

Freitas BC (0000-0002-3042-4192)* e Queluz DP (0000-0002-2998-1178)* contribuíram igualmente para a elaboração do manuscrito. 


\section{Referências}

1. Zilbovicius C. A saúde bucal e o Sistema Único de Saúde: integralidade seletiva em uma conjuntura neoliberal [dissertação]. São Paulo: Universidade de São Paulo, Faculdade de Odontologia; 2005.

2. Brasil. Lei $n^{0} 8.080$, de 19 de setembro de 1990. Regulamenta o Sistema Único de Saúde. Diário Oficial da União, 20 Set 1990. [acesso em 2020 jul 6]. Disponível em: http://www.planalto.gov.br/ccivil_03/leis/ 18080.htm.

3. Brasil. Ministério da Saúde, Conselho Nacional de Saúde. In: Relatório Final da $2^{\text {a }}$ Conferência Nacional de Saúde Bucal. 25 a 27 de setembro de 1993. [acesso em 2020 jul 6] Disponível em: https://pesquisa.bvsalud.org/portal/resource/pt/lil-144379.

4. Aquilante AG, Aciole GG. Construindo um "Brasil Sorridente"? Olhares sobre a implementação da Política Nacional de Saúde Bucal numa região de saúde do interior paulista. Cad. Saúde Pública. 2015; 31(1):82-96.

5. Brasil. Ministério da Saúde, Secretaria de Atenção à Saúde, Departamento de Atenção Básica. Diretrizes da Política Nacional de Saúde Bucal. 2004. [acesso em 2020 dez 5]. Disponível em: http://dab.saude.gov.br/ portaldab/biblioteca.

6. Scherer CI, Scherrer MD. Avanços e desafios da saúde bucal. Rev Saúde Pública. 2015; 49:98.

7. Chaves SCL, Almeida AMFL, Reis CS, et al. Política de Saúde Bucal no Brasil: as transformações no período 2015-2017. Saúde debate. 2018; 42(2):76-91.

8. Brasil. Ministério da Saúde, Secretaria de Atenção à Saúde, Departamento de Atenção Básica. Saúde Bucal. Brasília, DF: Ministério da Saúde; 2008.

9. Brasil. Constituição da República Federativa do Brasil. Brasília, DF: Senado Federal; 1988.

10. World Health Organization. United Nations Economic and Social Council. General comment $n^{\circ} 14$ : the right to the highest attainable standard of health [internet]. Geneva: WHO; 2000 [acesso em 2019 jul 5]. Disponível em: https://digitallibrary.un.org/ record/425041.

11. World Health Organization. A conceptual framework for action on the social determinants of health [internet]. Geneva: WHO; 2010 [acesso em 2019 maio 20]. Disponível em: https://www.who.int/social_determinants/thecommission/finalreport/en/.

12. Martinez GR, Albuquerque $\mathrm{A}$. $\mathrm{O}$ direito à saúde bucal na Declaração de Liverpool. Rev. bioét. (Impr.). 2017; 25(2):224-33.

13. Andrade GRB, Vaitsman J. Apoio social e redes: conectando solidariedade e saúde. Ciênc. Saúde Colet. 2002; 7(4):925-934.

14. Fernandes ETP, Ferreira EF. Consciência do Direito ao Atendimento Odontológico entre Usuários de uma Clínica de Ensino. Saúde Soc. São Paulo. 2010; 19(4):961-968.

15. Asensi F. Judicialização da Saúde e Conselho Nacional de Justiça. Perspectivas e desafios. In: Nobre M, Silva R, organizadores. O CNJ e os desafios da efetivação do direito à saúde. Belo Horizonte: Fórum; 2013. p. 85-111.

16. Ventura M, Simas L, Pepe VLE, et al. Judicialização da saúde, acesso à justiça e a efetividade do direito à saúde. Physis. 2010; 20(1):77-100.

17. Schulze CJ. Números atualizados da Judicialização da Saúde no Brasil. [acesso em 2019 out 16]. Disponível em: https://emporiododireito.com.br/leitura/ numeros-atualizados-da-judicializacao-da-saude-no-brasil-por-clenio-jair-schulze.

18. Nobre MAB, Silva RAD, organizadores. O CNJ e os Desafios da Efetivação do Direito à Saúde. 2. ed. Belo Horizonte: Fórum; 2013.

19. Scheffer M. Coberturas assistenciais negadas pelos 
planos e seguros de saúde em ações julgadas pelo Tribunal de Justiça do Estado de São Paulo. R. Dir. sanit. 2013; 14(1):122-132.

20. Chieffi AL, Barradas RCB, Golbaum M. Legal access to medications: a threat to Brazil's public health system? BMC Health Serv Res. 2017; 19(17):499.

21. Biehl J, Socal MP, Amon JJ. The Judicialization of Health and the Quest for State Accountability: Evidence from 1,262 Lawsuits for Access to Medicines in Southern Brazil. Health and Human Rights. 2016; 18(1)209-220.

22. Fonseca EP, Fonseca SGO, Meneghim MC. Análise do acesso aos serviços odontológicos públicos no Brasil. BCS Health Sci. 2017; 42(2):85-92.

23. Instituto Brasileiro de Geografia e Estatística. São Paulo. [acesso em 2020 jun 4]. Disponível em: https://cidades.ibge.gov.br/brasil/sp/panorama.
24. Cavalcanti AL, Silva ALO, Santos BF, et al. Odontologia e o Código de Defesa do Consumidor: análise dos processos instaurados contra cirurgiões-dentistas e planos odontológicos em Campina Grande - Paraíba. Rev Odontol UNESP. 2011; 40(1):6-11.

25. Setton MGJ. A teoria do habitus em Pierre Bourdieu: uma leitura contemporânea. Rev. Bras. Educ. 2002; 20:60-70.

26. Fonseca LLV, Nehmy RMQ, Mota JAC. O valor social dos dentes e o acesso aos serviços odontológicos. Ciênc. Saúde Colet. 2015(10):3129-3138.

27. Narvai PC, Frazão P. Saúde bucal no Brasil: muito além do céu da boca. Rio de Janeiro: Fiocruz; 2008. (Coleção Temas em Saúde).

Recebido em 13/01/2020

Aprovado em 08/06/2020

Conflito de interesses: inexistente

Suporte financeiro: não houve 